\title{
Guidance on priority setting in health care (GPS-Health): the inclusion of equity criteria not captured by cost-effectiveness analysis
}

\author{
Ole F Norheim ${ }^{1 *}$, Rob Baltussen ${ }^{2}$, Mira Johri ${ }^{3}$, Dan Chisholm ${ }^{4}$, Erik Nord ${ }^{5}$, DanW Brock ${ }^{6}$, Per Carlsson ${ }^{7}$, \\ Richard Cookson ${ }^{8}$, Norman Daniels ${ }^{9}$, Marion Danis ${ }^{10}$, Marc Fleurbaey ${ }^{11}$, Kjell A Johansson ${ }^{1}$, Lydia Kapiriri ${ }^{12}$, \\ Peter Littlejohns ${ }^{13}$, Thomas Mbeeli ${ }^{14}$, Krishna D Rao ${ }^{15}$, Tessa Tan-Torres Edejer ${ }^{3}$ and Dan Wikler ${ }^{9}$
}

\begin{abstract}
This Guidance for Priority Setting in Health Care (GPS-Health), initiated by the World Health Organization, offers a comprehensive map of equity criteria that are relevant to health care priority setting and should be considered in addition to cost-effectiveness analysis. The guidance, in the form of a checklist, is especially targeted at decision makers who set priorities at national and sub-national levels, and those who interpret findings from cost-effectiveness analysis. It is also targeted at researchers conducting cost-effectiveness analysis to improve reporting of their results in the light of these other criteria.

The guidance was develop through a series of expert consultation meetings and involved three steps: i) methods and normative concepts were identified through a systematic review; ii) the review findings were critically assessed in the expert consultation meetings which resulted in a draft checklist of normative criteria; iii) the checklist was validated though an extensive hearing process with input from a range of relevant stakeholders.

The GPS-Health incorporates criteria related to the disease an intervention targets (severity of disease, capacity to benefit, and past health loss); characteristics of social groups an intervention targets (socioeconomic status, area of living, gender; race, ethnicity, religion and sexual orientation); and non-health consequences of an intervention (financial protection, economic productivity, and care for others).
\end{abstract}

Keywords: Priority setting, Resource allocation, Cost-effectiveness, Equity, Population health

\section{Introduction}

Priority setting of health interventions should seek to achieve health system goals, broadly defined as maximization of health, reduction of inequities in health, and financial protection against the costs of ill health [1,2]. Present methods for priority setting are poorly adapted to address the full range of health system objectives. The main approach to establishing health priority setting, cost-effectiveness analysis, addresses only the first objective of maximising health [3-12]. How governments and other responsible authorities balance health maximization with equity and financial protection has far-reaching implications for what health priorities are agreed and pursued [13]. Three is

\footnotetext{
* Correspondence: ole.norheim@igs.uib.no

'Department of Global Public Health and Primary Care, University of Bergen, PB 7800, 5020 Bergen, Norway

Full list of author information is available at the end of the article
}

therefore urgent need for a more explicit recognition of these additional concerns.

The present Guidance for Priority Setting in Health Care (GPS-Health) offers a checklist of equity criteria that are relevant to health care priority setting and are not adequately considered by cost-effectiveness analysis. Decision-makers should carefully consider these criteria alongside results of cost-effectiveness analyses when making decisions on the funding of one intervention and the refusal to fund another.

\section{Process of guidance development}

GPS-Health was develop through a series of expert consultation meetings and involved three steps: i) Methods and equity considerations were identified through a systematic review [14]. This review concluded that several viable techniques to integrate equity concerns within 
CEA now exist, ranging from descriptive approaches to quantitative methods. Two obstacles at the normative level have impeded their use in decision making to date: the multiplicity of concepts and values discussed under the rubric of equity, and the lack of a widely accepted normative source on which to ground controversial value choices. Clarification of equity concepts and attention to procedural fairness may strengthen use of these techniques in decision-making. ii) The expert group with representatives from the International Society on Priorities in Health Care, WHO, the National Institute for Health and Clinical Excellence (UK), decision makers from low- and middle income countries, and ethicists and health economists from various academic institutions - met to validate and refine the list of proposed normative criteria. iii) The draft document was presented to the International Society on Priority Setting in Health and other interested stakeholder to improve the recommendations. Input from this hearing process was used in the final revision of the document.

\section{Target groups and proposed use}

The guidance is especially targeted at decision makers who set priorities at national and sub-national levels and who interpret findings from cost-effectiveness analysis. It is intended to be used as a practical checklist that helps them to make sure they have considered all the main issues of equity that are not captured by cost-effectiveness analysis. It is also targeted at researchers conducting cost-effectiveness analysis to improve reporting of their results in the light of these other criteria. Clinicians, and others who want to participate in informed public debate, may also benefit from this guidance.

The guidance is particularly useful if evidence exists on the cost-effectiveness for a wide range of health interventions, and important choices need to be made on which intervention to fund, and for whom. WHO's CHOICE project has produced a large database of the cost-effectiveness of intervention, which could be one possible starting point for assessing the range or depth of services to be provided [15]. The Disease Control Priorities Project is another source containing relevant cost-effectiveness evidence [16]. Although special attention is given to low- and middle-income countries, this guidance is relevant in all settings [17].

\section{Principles for priority setting}

Priority setting in health is inevitable in all countries around the world. The choices a country makes will always positively or negatively affect some people in the population it serves. Decision makers are therefore accountable to justify their decisions to all those affected and demonstrate that they are aligned with the country's social values concerning health maximization, health distribution, and financial protection.

Cost effectiveness analysis identifies how resources should be allocated across health interventions so as to maximize health benefits within a given budget, or relative to a threshold level of societal willingness to pay [18]. Concerns about the distribution of health stem from the idea that every person in society should have a fair chance to live a long and healthy life [19]. This principle can be further expressed in terms of vertical equity (requiring the unequal treatment of relevantly unequal cases and pertaining to characteristics of the disease an intervention targets) and horizontal equity (requiring equal treatment of relevantly equal cases and pertaining to characteristics of social groups an intervention targets) [20-22]. The use of either cost-effectiveness analysis or equity analysis for priority setting may lead to different policy recommendations. The key difference is that the former is only concerned about the absolute size of health gains, whereas the latter is concerned about how these health gains are distributed among members of the population. This may lead to striking differences in e.g. provision of health interventions for HIV/AIDS control, in which cost-effectiveness analysis recommends a strategy of universal test and early treatment as an efficient way to reduce the epidemic [23], and equity analysis would suggest prioritizing treatment of severely ill people, mobile treatment services in rural service or food subsidies to poor people [24].

In addition, health interventions also have important consequences outside the health sector, and these may also determine whether certain interventions should be considered priorities. Most importantly, countries may wish to implement interventions that provide financial protection to their populations, in order to reduce poverty associated with ill health or catastrophic health expenditures.

\section{Criteria for priority setting}

The GPS-Health distinguishes three groups of criteria pertaining to i) the disease an intervention targets; ii) the characteristics of the social group an intervention targets; and iii) non-health consequences (Table 1). Below we present rationales for consideration of these criteria in the prioritisation of health interventions, in addition to cost-effectiveness analysis. Several other criteria were also considered, but excluded from the checklist (see Appendix).

\section{Group 1: disease-related criteria}

For equity reasons, decision-makers may want to attach special value to interventions that target severe health conditions, people with a low capacity to benefit or with large past health losses. 
Table 1 Priority-setting criteria to be considered in conjunction with cost-effectiveness results

\begin{tabular}{ll}
\hline Group 1: disease and intervention criteria \\
\hline Criteria & Question \\
Severity & Have you considered whether the \\
& intervention has special value because of \\
& the severity of the health condition \\
& (present and future health gap) that the \\
& intervention targets? \\
& Have you considered whether the \\
& intervention has more value than the \\
effect size alone suggests on the grounds & that it does the best possible for a patient \\
& group for whom restoration to full health \\
& is not possible? \\
& Have you considered whether the \\
intervention has special value because it \\
targets a group that has suffered \\
significant past health loss (e.g. chronic \\
disability)?
\end{tabular}

Group 2: criteria related to characteristics of social groups

Criteria

Question

Socioeconomic status

Have you considered whether the intervention has special value because it can reduce disparities in health associated with unfair inequalities in wealth, income or level of education?

Area of living

Gender

Have you considered whether the intervention has special value because it can reduce disparities in health associated with area of living?

Have you considered whether the intervention will reduce disparities in health associated with gender?

Race, ethnicity, religion and sexual orientation

Have you considered whether the intervention may disproportionally affect groups characterized by race, ethnicity, religion, and sexual orientation?

Group 3: criteria related to protection against the financial and social effects of ill health

Criteria

Question

Economic productivity

Have you considered whether the intervention has special value because it enhances welfare to the individual and society by protecting the target population's productivity?

Care for others

Have you considered whether the intervention has special value because it enhances welfare by protecting the target population's ability to take care of others?

Catastrophic health expenditures

Have you considered whether the intervention has special value because it reduces catastrophic health expenditures for the target population?

\section{Severity of health condition}

Numerous studies of public preferences show that people put a high value on interventions for particularly severe health conditions, even when they are comparatively less effective than other alternatives $[8,25,26]$.
Many ethical theories also defend giving additional weight to health benefits distributed to those who are worse off in terms of the severity of disease [27-30]. Severe health conditions can refer to a) present health status, b) future health status, or c) future health gap compared with a reference standard of healthy life expectancy. Interventions for such severe conditions are often cost-effective, but not always (see Example 1).

Example 1: Severity of disease and infliximab for fistulising Crohn's disease in UK:

In a recent recommendation from NICE on treatment with infliximab for fistulising Crohn's disease, the incremental cost-effectiveness ratio compared to standard care was found to be $€ 30,300$ per QALY gained, which is around, or somewhat higher, than the recommended threshold of approximately $€ 30000$ per QALY gained [31]. In the overall assessment, treatment with infliximab was nevertheless recommended for fistulising Crohn's because the severity of the condition was considered so high that it justified an adjustment of the threshold typically set: "Although this ICER was considered to be relatively high, the Committee considered the severity of the disease and noted that there were few treatment options available to these patients. The Committee therefore concluded that a planned course of treatment with infliximab for people with fistulising disease could be cost effective if the definition of severe disease was met." [31].

This example shows that severity of disease sometimes can be seen as an independent criterion for adjusting judgments based on cost-effectiveness only. Other examples of particularly severe health conditions include under-five deaths from infections and malnutrition, maternal deaths, severe maternal complications, chronic schizophrenia, severe bipolar depression, suicide in young age, traffic accidents, HIV, TB, cervical cancer in young age, or severe congenital disorders.

\section{Realization of potential}

From the principle of health maximisation follows that priority should be given to people who benefit most from treatment. However, capacity to benefit is not the only consideration because one may value realization of potentials and wish to offer equal chances to people with different potentials. Many ethicists argue that persons with less treatable health conditions should have just as much of a fair chance to benefit from health care $[32,33]$. For example, if two potential organ transplant recipients have a potential to benefit that differs, everything else alike, health maximization requires that the person with highest expected benefit should have the organ [34]. By contrast, many argue that equity requires that each be given as much of a fair chance as others (for example through a weighted lottery) to realize their 
potential. This egalitarian "fair chances" argument has support in the general public and among societal decision makers in several jurisdictions [32,33].

\section{Past health loss}

Concern for past health loss, for example due to chronic disability, is a criterion hitherto less discussed in the literature on priority setting. It derives its justification from a concern for equal lifetime health: all persons should have a fair chance to live a long and healthy life due to the intrinsic importance of health and its instrumental value in enabling fulfilment of life plans [35].

\section{Group 2: criteria related to characteristics of social groups} Equity in health related to characteristic of social groups has been defined as "the absence of systematic disparities in health between social groups who have different levels of underlying social advantage or disadvantage" [36]. Targeting health interventions to disfavoured groups may be viewed as appropriate when these compensate for underlying factors such as the social determinants of health [4], even when they are not cost-effective. In resource-limited settings, social group factors can be particularly relevant in terms of socio-economic status, area of residence, and gender.

\section{Socioeconomic status}

People with lower socioeconomic status (SES) should have a fair chance to live a full healthy life. Health inequalities related to SES may be unfair when they are the result of an unjust distribution of the socially controllable factors affecting population health [6]. These factors may include social determinants of health, traditional public health measures, and personal medical services. Health interventions to reduce these health inequalities, e.g. food subsidies for people living with HIV/ AIDS, hold therefore special value and deserve additional priority (see Example 2) [6,37-40]. However, decision makers should also note that interventions outside the health sector may represent a more effective way to reduce health disparities, such as improving female education (where relevant) or implementing effective regulatory or fiscal measures. Thus, disparities in health associated with non-health determinants of health could have far-reaching implications for judgments about resource allocation outside the health sector.

Example 2: Correcting for socio-economic inequality in Sweden:

Swedish politicians responsible for health care in the county councils $(n=449)$ were asked in a survey about their opinions on trade-offs between interventions that maximizes health vs. interventions that are less efficient but eliminate social inequalities. The scenario assumed that myocardial infarction mortality rate was $50 \%$ higher among blue-collar workers than among white collar workers, and that the most cost-effective intervention (i.e. that saved most lives) did not reduce the inequality. The Swedish politicians rejected to only maximise health, and expressed their willingness to sacrifice 15 of 100 preventable deaths to reduce social inequalities [41]. The example illustrates the concept of opportunity cost that is key to all thinking about fair and efficient distribution. The opportunity cost of a health intervention is the value of health forgone if resources are spent elsewhere. The politicians were explicitly thinking about how many extra people would die in order to help a disadvantaged group. Distribution of health benefits between socioeconomic groups matters to decision makers and in this case decision makers rejected allocation strictly according to cost-effectiveness rankings.

\section{Area of residence}

Inequalities in health associated with area of residence are often seen as unacceptable and geographic equity is an often-stated goal in national health policy documents. People living in different areas should all have a fair chance to live a full and healthy life, and this may mean that priority should be given to interventions that target those areas. Localization of clinics for HIV treatment is one example where this criterion is relevant [42]. Because the provision of health care in rural areas, with few people or long travel distances, can be considerably more costly than in urban areas, achieving geographic equity may imply relative loss in overall population health gain [43].

\section{Gender}

In its most general form, men and women should have a fair chance to live a full and healthy life. Since women tend to have a longer life expectancy than men, but lower health status over their lifetime, it is not possible to provide general guidance on whether interventions targeting men or women should be considered a priority. Since there are forms of unfair treatment for women in nearly all countries, however, a special check for genderrelated disparities should be considered. This concern is especially relevant for reproductive health services and interventions against domestic violence against women, but also for road traffic injuries among young males and tobacco control for men.

\section{Race, ethnicity, religion, and sexual orientation}

All people, independent of race, ethnicity, religion or sexual orientation, should have a fair chance to live a full and healthy life. This criterion is mainly a nondiscriminatory clause, referring to instances in which interventions may be less effective or more costly in certain ethnic groups; prevention of cardiovascular disease 
among the Maori may be one example. Decision makers should take this into account, and give special value to interventions targeting those groups.

\section{Group 3: criteria related to protection against the financial and social effects of ill health}

This third set of criteria refers to the financial and social protection that some interventions offer [44]. Because of these non-health consequences, these interventions hold special value, and decision makers may sometimes want to prioritize them even if they are not cost-effective.

\section{Economic productivity}

Some health interventions may hold special value as they increase economic productivity more than other interventions, thereby creating additional non-health welfare gains for all through the tax system or other transfer mechanisms $[45,46]$. Others think that the productivity argument discriminates against the non-productive [47]. Since there is disagreement about these concerns, they are inconsistently incorporated into cost-effectiveness analysis. As a minimum, decision-makers should check whether productivity gains are taken into account, and whether this is not discriminating against the non-productive.

\section{Care for others}

Some health interventions hold special value because they target people in the age where they typically take care of others, e.g. children or elderly. In societies with an extended family structure and less reliance on the state to provide welfare for children or the elderly, welfare for others is widely accepted and relevant to consider.

\section{Catastrophic health expenditures}

Households may be pushed into poverty or forced into deeper poverty because of high out-of-pocket expenditures for health care $[1,48]$. Protection against catastrophic health expenditures can reduce poverty and improve overall welfare in society [49]. Decision-makers could give priority to public financing of such high-costs interventions, $\mathrm{e}, \mathrm{g}$, through subsidised provision or insurance coverage (see Example 3) [50]. In high-income countries with fair financing of health services, this criterion is typically given little weight because insurance coverage is often broad and interventions rarely impose large out-of pocket expenditures [51]. In middle-income countries (and even in some high-income countries), it is often the case that treatment for many serious illnesses is not covered even in these countries. This criterion is therefore relevant and should always be considered.

Example 3: Dialysis to prevent catastrophic health expenditures in Thailand:

In 2007 Thailand included peritoneal- and hemodialysis for patients with end-stage renal disease in their tax-based universal health insurance scheme. The incremental cost-effectiveness ratio (ICER) of initial treatment with peritoneal dialysis was in 2007 estimated to be US $\$ 52,000$ per quality-adjusted life-year (QALY) gained compared with palliative care [52], and was by many interpreted as not cost-effective. Financial protection was repeatedly used in the policy debate to nevertheless including dialysis in the health insurance scheme: if dialysis for end-stage renal disease would not be covered, it would impose catastrophic health expenditures on patients and thereby push them and their families into poverty.

This example shows that financial protection matters to decision makers and the public, even for costineffective interventions. However, full coverage for all in the universal plan would protect against catastrophic expenditures, but it might also displace services that do much more good. The example shows that the trade-off between maximizing health and financial protection will produce winners and losers, and it is not clear that the health loss from replacing other services that are more cost-effective and fair is well enough justified by financial protection of a few.

\section{Conclusion}

The GPS-Health does not provide a formula or blueprint for equitable priority setting of health interventions but should serve as input to priority setting processes [53]. Decision-makers should consider the checklist in conjunction with cost-effectiveness analysis, and carefully consider the criteria they find relevant to their health system and political context.

Since efficiency, equity and financial protection are considerations that sometimes conflict with each other, decision makers need to weigh them against each other and make trade-offs. It should be recognized that, in a resource-constrained system, giving additional weight to something or someone implies that something or someone else will lose out. The inclusion of equity concerns must therefore always take opportunity costs into consideration.

Use of this guidance is compatible with the use of more quantitative approaches, for example multi criteria decision analysis, to consider equity in evaluations of health interventions through explicit weighing $[12,24,54,55]$. Another example is the use of so-called equity or distributive weights, which can incorporate special priority to the worst off $[14,56]$. A third example is a proposal in UK to quantify the value of distributional impact for value based assessments of health technologies [57]. Methods are also being developed to incorporate concern for poverty and financial risk protection in extended cost-effectiveness analysis [58].

Yet, there may always be disagreement about the importance of criteria when setting priorities between health interventions. For this reason, ethicists have stressed the 
importance of fair processes, which allow key stakeholders to agree on what is legitimate and fair. Key elements of a fair process involves transparency about the grounds for decisions; appeals to rationales that all can accept as relevant to meeting health needs fairly; and procedures for revising decisions in light of challenges to them. Together these elements assure "accountability for reasonableness." [53]. The GPS-Health should therefore be seen as integral to such legitimate processes.

The GPS-Health feeds into the international debate about social value judgements [59] and the use of different criteria for priority setting in health care, in two ways. First, the present guidance can be considered as complementary to published inventories and mapping of all possibly relevant criteria $[12,56]$ as it is based on intense deliberative processes between experts on the relevance of these criteria and ultimately consensus building $[12,60]$. Second, many countries around the world mention equity-related criteria in their policy frameworks on the reimbursement of health interventions, but these are sometimes ill-defined and not operationalized [61]. This may be one reason why value judgements other than health maximization are not routinely used in important coverage decisions. The GPS-Health aims to overcome this barrier by offering a ready-to-use checklist to decision-makers. This may help them to make the right decisions on the funding of one intervention and the refusal to fund another.

\section{Appendix: criteria excluded from the checklist}

Life threatening conditions is a sub-category of severity and is often a key concern in public debate about priority setting decisions. For example, cancer with metastasis may be life threatening, and interventions that save or extend life for people with such conditions may therefore be assigned very high priority by some. But threat to life cannot be the sole condition of priority. Sometimes interventions with marginal benefits and extremely high costs should not be prioritized. The underlying concern is better captured by the severity criterion combined with effectiveness considerations.

\section{Age}

This guidance does not propose age as an independent criterion. The combination of criteria will indirectly imply some priority to the young. Cost-effectiveness analysis will typically, but not always, favour interventions targeting younger age groups. The productivity criterion also indirectly assigns less value to health gained in old age. Severity and past health loss may often, but not always, favour the young. The more general principle that all persons should have a fair chance to live a long and healthy life will in most cases favour the young, but the justification is not age itself, but who the worst off are in terms of lifetime health. The expert group did not consider whether health gains for the very young should have different marginal weights than for adults $[45,62,63]$.

\section{Individual responsibility for health}

In some instances, potential beneficiaries have an existing health condition clearly associated with past choices or a known risky behaviour with a clear association with future health problems. It could be reasonable to considered whether the intervention has lower value because individuals bears some responsibility and has ability to pay for their own care. Whether governments should also hold individuals responsible for choices that affect health and risk is a controversial question. Health conditions are generally due to a combination of background factors, luck and behaviour, and it is therefore unacceptable to submit patients to differential health care access or financial conditions, unless this respects their own values and preferences [32,64-68].

\section{Rarity of health condition}

Rare conditions, i.e. those with a very low prevalence $(<5$ cases per 10000 ), pose a special challenge for priority setting. Rarity is in itself not ethically relevant. However, rare conditions are often particularly costly to treat because product development costs can only be spread over relative few patients, and interventions may therefore be cost-ineffective. Evidence may also be weak because a small patient population makes it difficult to conduct high quality randomized clinical trials. To some extent the cost problem and the documentation problem are balanced by the fact that the value of treatments for rare conditions is in many cases augmented by other equity concerns, such as concerns for severity and concerns for realization of potentials/fair chances. However, this balancing occurs in far from all rare diseases. To ensure equal access to treatment for patients with rare diseases it is therefore sometimes argued that there should be a higher willingness to pay for treatments for rare conditions than for treatments in general. The problem is that this would give an advantage to patients with rare diseases relative to patients with more common diseases who are costly to treat for other reasons than rarity. Altogether the group did not agree on how rare diseases should be dealt with, but a majority wanted it excluded from the main list of equity criteria on the grounds that rarity is not a value per se.

\section{Competing interests}

The authors declare that they have no competing interests.

\section{Authors' contribution}

OFN, MJ, RB, DC and TTE had the original idea for this paper. OFN, MJ, RB and DC wrote the first draft, and all authors met three times to discuss, review and comment on the draft. All authors provided written comments on subsequent drafts. All authors read and approved the final manuscript. 


\section{Acknowledgements}

This work was undertaken in collaboration with the World Health Organization's Cost-effectiveness and Priority-setting (CEP) unit. The idea of developing a standardized instrument for priority setting was proposed by Mira Johri, Dan Chisholm and Ole F. Norheim at a June, 2009 workshop in Arusha, Tanzania. Participants at a September 2010 workshop hosted jointly by the World Health Organization (WHO)'s Cost-effectiveness and Priority-setting (CEP) unit in Geneva, Switzerland, the International Society on Priorities in Health Care, and the University of Bergen, reviewed results and refined concepts to be included in the guidance. The hearing process for feedback on the guidance document included an experts' meeting at the Brocher Foundation, Geneva, June 16-17, 2011 and written input from members of the International Society for Priorities in Health Care and others: Alicia Yamin, Andy Oxman, Atle Fretheim, Berit Mørland, Bona M. Chita, Cam Donaldson, Camila Gianella, Greg Bognar, Joseph Millum, Kristine Bærøe, Kristine Onarheim, Mireille Goetghebeur, Tammy Clifford, Toby Ord, and Yukiko Asada. We especially thank Babu Ahmed, Chen Jie, VijjKasempsup, Lydia Kapiriri, Ramanan Laxminarayan, Noor Tromp, Jake Marcus, Marie-Gloriose Ingabire, Sharmila Mhatre, and Ånen Ringard for presentations and input during the consultations.

\section{Financial statement}

The first meeting to develop the guidance document in Geneva September 2010 was funded by a Young Investigator Grant for Ole F. Norheim, Norwegian Research Council (grant no 611720). The Brocher Foundation provided support for the second meeting of experts in June 2011. MJ acknowledges a New Investigator Award from the Canadian Institutes for Health Research (CIHR). The funders had no role in study design, data collection and analysis, decision to publish, or preparation of the manuscript.

\section{Disclaimer}

DC and TIT are staff members of the World Health Organization. The authors alone are responsible for the views expressed in this publication and they do not necessarily represent the decisions, policy or views of the World Health Organization.

\section{Author details}

${ }^{1}$ Department of Global Public Health and Primary Care, University of Bergen, PB 7800, 5020 Bergen, Norway. ${ }^{2}$ Nijmegen International Centre for Health Systems Research and Education (NICHE), Radboud University Nijmegen Medical Centre, Nijmegen, The Netherlands. ${ }^{3}$ Centre de Recherche du Centre Hospitalier de I'Université de Montréal (CRCHUM), Québec, Canada. ${ }^{4}$ Department of Health Systems Financing, World Health Organization, Geneva, Switzerland. ${ }^{5}$ Norwegian Institute of Public Health, Oslo, Norway. ${ }^{6}$ Harvard Medical School, Harvard University, Cambridge, USA. ${ }^{7}$ National Centre for Priority Setting in Health Care, Linköping University, Linköping, Sweden. ${ }^{8}$ Centre for Health Economics, University of York, York, UK. ${ }^{9}$ Harvard School of Public Health, Harvard University, Cambridge, USA. ${ }^{10}$ Section on Ethics and Health Policy, NIH Clinical Centre, Bethesda, USA. ${ }^{11}$ Woodrow Wilson School of Public and International Affairs, Princeton University, Princeton, USA. ${ }^{12}$ Department of Health, Aging, and Society, McMaster University, Hamilton, Canada. ${ }^{13}$ Department of Primary Care and Public Health Sciences, Division of Health and Social Care Research, King's College London, Previous affiliation the National Institute for Health and Care Excellence (NICE), London, England, UK. ${ }^{14}$ Ministry of Health and Social Services, Windhoek, Namibia. ${ }^{15}$ Public Health Foundation of India, New Delhi, India.

\section{Received: 5 April 2014 Accepted: 18 July 2014}

Published: 29 August 2014

\section{References}

1. World Health Report: Financing for Universal Coverage. Geneva: World Health Organization; 2010.

2. WHO: Making fair choices on the path to universal health coverage. Final report of the WHO Consultative Group on Equity and Universal Health Coverage. Geneva: World Health Organization; 2014. Available from: http://www.who.int/choice/documents/making_fair_choices/en/. [cited 2014 May 10].

3. Sassi F, Archard L, Le Grand J: Equity and the economic evaluation of healthcare. Health Technol Assess 2001, 5:3.
4. Weatherly H, Drummond M, Claxton K, Cookson R, Ferguson B, Godfrey C, Rice N, Sculpher M, Sowden A: Methods for assessing the cost-effectiveness of public health interventions: key challenges and recommendations. Health Policy 2009, 93(2-3):85-92.

5. Hauck K, Smith PC, Goddard M: The Economics of Priority Setting in Health Care. Washington, D.C., USA: The International Bank for Reconstruction and Development/ The World Bank; 2003.

6. Daniels N: Just Health: Meeting Health Needs Fairly. Cambridge: Cambridge University Press; 2008.

7. Brock D, Wikler D: Ethical Issues in Resource Allocation, Research, and New Products Development. In Disease Control Priorities in Developing Countries. 2nd edition. Edited by Jamison D, Breman J, Measham A, et al. New York: Oxford University Press and the World Bank; 2006.

8. Nord E, Daniels N, Kamlet M: QALYs: Some Challenges. Value Health 2009, 12(Supplement 1):S10-S15.

9. Nord E: Towards cost-value analysis in health care? Health Care Anal 1999, 7(2):167-175.

10. Baltussen R, Stolk E, Chisholm D, Aikins M: Towards a multi-criteria approach for priority setting: an application to Ghana. Health Econ 2006, 15(7):689-696.

11. Brock DW: Ethical Issues in the Use of Cost Effectiveness Analysis for the Prioritization of Health Care Resources. In Making Choices in Health: WHO Guide to Cost-Effectiveness Analysis. Edited by Tan-Torres Edejer T, Baltussen R, Adam T, Hutubessy R, Acharya A, Evans DB, et al. Geneva: World Health Organization; 2003:289-312.

12. Tromp N, Baltussen R: Mapping of multiple criteria for priority setting of health interventions: an aid for decision makers. BMC Health Serv Res 2012, 12:454.

13. Fleurbaey M, Schokkaert E: Equity in health and health care. In Handbook of Health Economics. Edited by Pauly M, McGuire T, Pita-Barros P. North-Holland; 2011.

14. Johri M, Norheim OF: Can cost-effectiveness analysis integrate concerns for equity? Systematic review. Int J Technol Assess Health Care 2012, 28(2):125-132.

15. WHO: CHOosing Interventions that are Cost Effective (WHO-CHOICE). ; 2012. [cited 201215 August]; Available from: http://www.who.int/choice/en/.

16. DCP3: Disease control priorities project 3. [cited June 2013]; Available from: http://www.dcp-3.org/.

17. Registry TC-E: 2014. [cited 2014 June 25]; Available from: https://research. tufts-nemc.org/cear4/Home.aspx.

18. Drummond MF, Sculpher MJ, Torrance GW, O'Brien BJ, Stoddart GL: Methods for the Economic Evaluation of Health Care Programmes. 3rd edition. New York: Oxford University Press; 2005.

19. Williams A: Intergenerational equity: an exploration of the 'fair innings' argument. Health Econ 1997, 6(2):117-132.

20. Culyer AJ, Wagstaff A: Equity and equality in health and health care. J Health Econ 1993, 12(4):431-457.

21. Wagstaff A, van Doorslaer E: Equity in Health Care Finance and Delivery. In Handbook of Health Economics, Volume 1. Edited by Culyer AJ, Newhouse JP. Elsevier; 2000.

22. Musgrove P: Public spending on health care: how are different criteria related? Health Policy 1999, 47(3):207-223.

23. Hontelez J, Lurie M, Bärnighausen T, Bakker R, Baltussen R, Tanser F, Hallett TB, Newell ML, de Vlas SJ: Elimination of HIV in South Africa through expanded access to antiretroviral therapy: a model comparison study. PLoS Med 2013, 10:10

24. Baltussen R, Mikkelsen E, Tromp N, Hurtig A, Byskov J, Olsen Ø, Bærøe K, Hontelez JA, Singh J, Norheim OF: Balancing efficiency, equity and feasibility of HIV treatment in South Africa - development of programmatic guidance. Cost Eff Resour Alloc 2013, 11(1):26.

25. Dolan P, Shaw R, Tsuchiya A, Williams A: QALY maximisation and people's preferences: a methodological review of the literature. Health Econ 2005 14(2):197-208.

26. Nord E, Pinto JL, Richardson J, Menzel P, Ubel P: Incorporating societal concerns for fairness in numerical valuations of health programmes. Health Econ 1999, 8(1):25-39.

27. Daniels N: Four unsolved rationing problems. A challenge. Hastings Cent Rep 1994, 24(4):27-29.

28. Brock D: Priority to the Worse Off in health-Care Resource Prioritization. In Medicine and Social Justice. Edited by Rhodes R, Battin M, Silvers A. Oxford: Oxford University Press; 2002:362-372.

29. Ottersen T: Lifetime QALY prioritarianism in priority setting. J Med Ethics 2013, 39(3):175-180. 
30. Norheim OF: Clinical priority setting. BMJ 2008, 337:a1846. doi:10.1136/bmj.a1846.

31. National Institute of Health and Clinical Excellence: Infliximab (review) and adalimumab for the treatment of Crohn's disease. May 2010. London: National Institute of Health and Clinical Excellence; 2010.

32. Nord E: Cost-Value Analysis in Health Care: Making Sense Out of QALYS. New York: Cambridge University Press; 1999.

33. Caro J, Nord E, Siebert U, McGuire A, McGregor M, Henry D, de Pouvourville G, Atella $\mathrm{V}$, Kolominsky-Rabas P: The efficiency frontier approach to economic evaluation of health-care interventions. Health Econ 2010, 19(10):1117-1127

34. Brock D: Ethical Issues in Recipient Selection for Organ Transplantation. In Organ Substitution Technology. Edited by Matthieu D. Boulder CO: Westview Press; 1988.

35. Norheim OF, Asada Y: The ideal of equal health revisited: definitions and measures of inequity in health should be better integrated with theories of distributive justice. Int J Equity Health 2009, 8:40.

36. Braveman P, Gruskin S: Defining equity in health. J Epidemiol Community Health 2003, 57(4):254-258.

37. Sen A: Why health equity? Health Econ 2002, 11:659-666. 2002;11:659-66.

38. Marmot M, Allen J, Goldblatt P, Boyce T, McNeish D, Grady M, Geddes I: Fair Society, Healthy Lives: the Marmot Review. London: Ministry of Health UK; 2010.

39. Marmot M, Friel S, Bell R, Houweling TA, Taylor S: Closing the gap in a generation: health equity through action on the social determinants of health. Lancet 2008, 372(9650):1661-1669.

40. Daniels N, Kennedy B, Kawachi I: Why justice is good for our health: the social determinants of health inequalities. Daedalus 1999, 128(4):215-251.

41. Lindholm L, Rosen M: On the measurement of the nation's equity adjusted health. Health Econ 1998, 7(7):621-8.

42. Daniels N: Fair process in patient selection for antiretroviral treatment in WHO's goal of 3 by 5. Lancet 2005, 366(9480):169-171.

43. Baltussen R, Johri M, Norheim OF: Fairness in service choice: an important yet underdeveloped path to universal coverage. Trop Med Int Health 2010, 16(17):838-839.

44. Fleurbaey M, Luchini S, Muller C, Schokkaert E: Equivalent incomes and the economic evaluation of health care. Health Econ 2013, 22:711-729.

45. Murray C: Rethinking DALYs. In The Global Burden of Disease. Edited by Murray C, Lopez A. Cambridge Mass: Harvard School of Public Health, WHO, World Bank; 1996:1-98

46. Murray CJ, Acharya AK: Understanding DALYs (disability-adjusted life years). J Health Econ 1997, 16(6):703-730.

47. Brock DW: Separate spheres and indirect benefits. Cost Eff Resour Alloc 2003, 1(1):4.

48. McPake B: User charges for health services in developing countries: a review of the economic literature. Soc Sci Med 1993, 36(11):1397-1405.

49. Hauck K, Smith P, Goddard M: The Economics of Priority Setting for Health: a Literature Review. Washington DC: The World Bank; 2002.

50. Smith P: Incorporating financial protection into decision rules for publicly financed healthcare treatments. Health Econ 2013, 22:180-193.

51. Smith P: User charges and priority setting in health care: balancing equity and efficiency. J Health Econ 2005, 24:1018-1029.

52. Teerawattananon Y, Mugford M, Tangcharoensathien V: Economic evaluation of palliative management versus peritoneal dialysis and hemodialysis for end-stage renal disease: evidence for coverage decisions in Thailand. Value in health 2007, 10(1):61-72.

53. Daniels N, Sabin JE: Setting Limits Fairly: Can We Learn to Share Medical Resources?. 2nd edition. Oxford: Oxford University Press; 2008.

54. Youngkong S, Kapiriri L, Baltussen R: Setting priorities for health interventions in developing countries: a review of empirical studies. Trop Med Int Health 2009, 14(8):930-939.

55. Youngkong S, Baltussen R, Tantivess S, Mohara A, Teerawattananon Y: Multicriteria decision analysis for including health interventions in the Universal Health coverage benefit package in Thailand. Value Health 2012, 15:961-970.

56. James C, Carrin G, Savedoff W, Hanvoravongchai P: Clarifying efficiency-equity tradeoffs through explicit criteria, with a focus on developing countries. Health Care Anal 2005, 13(1):33-51.

57. National Institute for Health and Clinical Excellence, Centre for Health Technology Evaluation: Value Based Assessment of Health Technologies. London: NICE; 2014.

58. Verguet $S$, Laxminarayan $R$, Jamison DT: Universal Public Finance of Tuberculosis Treatment in India: An Extended Cost-Effectiveness Analysis. Disease Control Priorities in Developing Countries. Health Econ 2014 Feb 4. doi:10.1002/hec.3019.
59. Littlejohns P, Weale A, Chalkidou K, Faden R, Teerawattananon Y: Social values and health policy: a new international research programme. J Health Organ Manag 2012, 26(3):285-292.

60. Tanios N, Wagner M, Tony M, Baltussen R, van Til J, Rindress D, Kind P, Goetghebeure M: Which criteria should be considered in health care decisions? Insights from an international survey of policy and clinical decisopn makers. Int J Techn Assessment 2013, 2013 (in press).

61. Golan O, Hansen P, Kaplan G, Tal O: Health technology prioritization: which criteria for prioritizing new technologies and what are their relative weights? Health Policy 2011, 102(2-3):126-135.

62. Persad G, Wertheimer A, Emanuel EJ: Principles for allocation of scarce medical interventions. Lancet 2009, 373(9661):423-431.

63. Kerstein SJ, Bognar G: Complete lives in the balance. Am J Bioeth 2010, 10(4):37-45.

64. Cappelen AW, Norheim OF: Responsibility in health care: a liberal egalitarian approach. J Med Ethics 2005, 31(8):476-480.

65. Daniels N: Democratic Equality: Rawls's Complex Egalitarianism. In The Cambridge Companion to Rawls. Edited by Freeman S. Cambridge: Cambridge University Press; 2003:241-276

66. Daniels N: Social and Individual Responsibility for Health. In Distributive Justice and Responsibility. Edited by Knight C, Stemplowska Z. Oxford and New York: Oxford University Press; 2011:266-287.

67. Wikler D: Personal and Social Responsibility for Health. In Public Health, Ethics, and Equity. Edited by Anand S, Peter F, Sen AK. Oxford: Oxford University Press; 2004:109-134.

68. Marchand S, Wikler D, Landesman B: Class, health and justice. Milbank Mem Fund Q 1998, 76(3):449-467.

\section{doi:10.1186/1478-7547-12-18}

Cite this article as: Norheim et al: Guidance on priority setting in health care (GPS-Health): the inclusion of equity criteria not captured by cost-effectiveness analysis. Cost Effectiveness and Resource Allocation 2014 12:18.

\section{Submit your next manuscript to BioMed Central and take full advantage of:}

- Convenient online submission

- Thorough peer review

- No space constraints or color figure charges

- Immediate publication on acceptance

- Inclusion in PubMed, CAS, Scopus and Google Scholar

- Research which is freely available for redistribution 